\title{
Aspects of Salience in Phatic Tokens
}

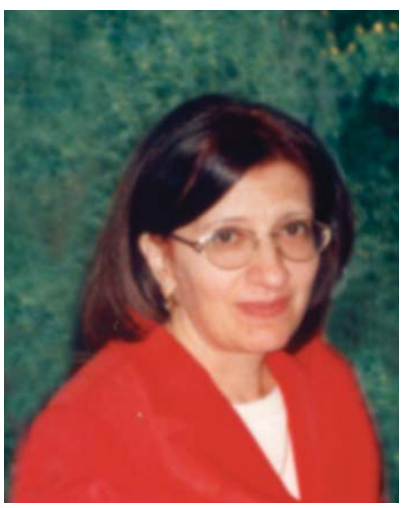

Shoushan Paronian
$\boldsymbol{T}$ he pragmatic perspective requires the study of

1 linguistic phenomena from the point of view of their usage. Pragmalinguists define language use as "the making of linguistic choices, taking into account the mediating role of both the utterer's and the interpreter's m i n d s" (Verschueren, 1999:187). Pragmalinguistic analysis assigns an essential role to consciousness in language use, trying to reveal different levels of linguistic knowledge - conscious, subliminal or automatic (i.e. unconscious) - in the process of production and interpretation of speech.

Acknowledging the role of cognition in the process of verbal interaction, we agree with J.Verschueren who states that "not everything that happens in linguistic behaviour occupies the same place in consciousness" (Verschueren, 1999:173 ). It is, therefore, not surprising that verbal interaction can be associated with different points of consciousness. Thus, in certain stereotypical situations and previously planned speech events ready-made conversational formulae and practiced structures are put to use with no conscious effort: the speaker automatically reproduces these speech tokens or he just repeats the stored knowledge, adapting it to the actual needs of communication with the help of spontaneous recognition. Accordingly, in non-stereotypical situations creativity and conscious outwork - cognizant usage of linguistic structures and forms - are necessary to make the linguistic choices. In this case the speaker necessarily exercises quite a different mental action which, according to cognitive psychologists, requires more conscious operations than spontaneous recognition - active recall.

In the present article I shall be concerned with the problem of actual choice of linguistic units - the relation between generation of meaning and language use. I will try to show how different degrees of salience - conscious choice of words for various communicative needs - operate in the process of verbal interaction, enabling the speakers to repeat ready-made phrases retrieved from memory or to create new ones. The analysis is based on the assumption that speech is a kind of social action governed by linguistic norms and stereotypes - ideas based on certain kinds of experiences which symbolize some kind of general behaviour.

Speaking about language as a kind of social action, some analysts suppose that most interlocutors share a certain amount of background knowledge about 'proper' behaviour and the 'right' way to do things. J.Cutting, for example, assumes that there are numerous stereotypes - ideas that we have about the "typical" behaviour and characteristics of 
people or objects (Cutting J., 2002). Expanding on the problem of processing (production of speech and understanding), G.Brown and G.Yule state that the latter depends on activating a small part of background knowledge at a time (Brown, Yule, 1983). It follows that there must be some way in which knowledge is organized and stored to allow easy access. This idea brings us close to the role of knowledge in speech.

Trying to understand how knowledge of the world and language interact, discourse analysts resort to certain findings in the field of Artificial Intelligence, namely to the concept of knowledge schemata - mental representations that try to modelize human language competence and human knowledge. In principle, schemata are data structures representing stereotypical patterns which we retrieve from our mental storage - memory - and employ in our understanding of discourse.

Research work carried out in the field of cognitive linguistics shows that the knowledge the speakers possess concerning social interaction via language is just one part of their general socio-cultural knowledge. People create mental models based upon dicourse, the situation and the purposes they have to serve: schemas, scripts, scenarios, frames, mental models. These models refer to certain mental activities involved in language use: perception (reading or interpretation), representation (production of discourse), as well as planning (Clark H., 2002; Verschueren J., 1999; Паронян Ш., 2003). All these activities, as we see, have to do with a single mental operation processing of information in memory. The most important conclusion we can draw from all this is that the search for proper strategies to speak enables the addressee to make use of scripts, i.e. mental representations of activity or event types, stored in his memory in the form of background knowledge.

As I have already stated, my report deals with the problem of salience of linguistic choices. I shall try to show the role of mental models in the process of communication on the example of phatic tokens.

First of all, it is necessary to clarify what we understand by saying 'phatic tokens'.

It goes without saying that one way of analyzing language is looking at language in terms of social functions it serves. In this case language can be seen as 'social semiotic' - a system of signs which serves the social organization and communicative requirements of the human society. Such being the case, the terms "phatic communication" and "phatic function”, introduced by B.Malinovsky and R.Jakobson, can be treated as linguistic notions that deal with cultural and communal needs of language users (Malinovsky B., 1936; Jakobson R., 1975).

It should be noted that the linguists are unanimous in their evaluation of the phatic function of language. The latter is defined as the process of "opening and closing the channel, checking that it is working for practical or social reasons” (Cook G., 2002:25).

Things are different with the interpretation of phatic communication. On the one hand, it is customary to treat phatic communication as the conventional use of language to open and close talk exchanges. Thus, some linguists assume that phatic communication is information which the interlocutors exchange for the sake of politeness. It is made up of statements that are aimed at the establishment, maintenance and termination of verbal contact (Почепцов Г., 1981). It has also been proposed to 
limit phatic tokens to instances of communicative initiation (greetings) that mark the beginning of the conversation.

On the other hand, starting from a different theoretical basis, sociolinguists and conversation analysts have pointed out some more profound qualities of phatic communication which enable them to serve the social needs of communication. On account of this, phatic tokens have been treated as speech units that establish agreement, unification and harmony in the process of communication.

As we see, the first approach focuses on the conversational-regulating aspect of phatic communication: phatic tokens are treated as conventional linguistic signs, fixed for certain procedural needs of communication. For example, Good morning; Good evening; Hello; Bye, etc.

The second approach comes to prove that phatic communication can also perform a social-regulating function: it serves the social needs of communication, establishing and maintaining social relationships through language use. The idea about the social function of phatic tokens has been introduced within the frames of linguistic analyses. Thus, according to B.Malinovsky, "phatic communication is a kind of speech in which the ties of agreement, unification are formed with the simple exchange of words” (Malinovsky B., 1936:515). M.Halliday has also noted the social aspect of phatic communication in his ideational function of language - the function the language serves to establish as basis for cooperative action and social relations (Halliday, 1975). Stressing the social facet of phatic communication, A.Capone proposes a classification of phatic tokens which is based on the social factor. Thus, he supposes that phatic tokens are ways of showing status by orienting comments to oneself, the other or to the general or prevailing situation. Accordingly, he distinguishes between three types of phatic tokens: 1.Self-oriented: phatic tokens that are personal to the speaker (for example, asides like I'm not up to this or My feet are killing me); 2.Other-oriented: phatic tokens that are related to the hearer (For example, Do you work here?; You seem to know what you're doing); 3.Neutral: tokens that refer to the context or general state of affairs (Cold, isn't it?; Lovely flowers) (Capone A., 2003).

It should be noted that discourse analysts point out the importance of establishing common ground and agreeing points of view in the process of communication. Such being the case, it is currently accepted to distinguish between two functions of speech transactional and interactional. G.Brown and G.Yule, for example, include phatic communication within the sphere of the interactional function whose aim is to establish common ground between the interlocutors, to show solidarity and maintain social cohesion, lacking cohesion of meaning. Thus, it is not far from likely that phatic communication can be treated as language with no information content as it is noninformative. Nevertheless, phatic tokens are undoubtedly important strategic means in the process of communication since they do not simply function to keep the channel of communication open: with the help of these strategic means the speakers maintain agreement, harmony which is absolutely necessary for the successful management of communication. With this view in mind, it is quite possible to treat phatic 
communication as a special kind of face-saving act arising out of needs of the interlocutors.

As we know, one of the aims of Discourse Analysis is to establish tied and meaningful component units within a linked and co-ordinated whole - discourse. For this purpose different types of tied sequences - exchanges, transactions, adjacency pairs have been submitted to pragmalinguistic analysis. The analysis of phatic communication has revealed a special unit of tied utterances - phatic discourse. On this account, it is customary to distinguish phatic discourse as a type of adjacency pairing that includes routine greetings and partings, attempts to establish or check contact in face-to-face interactions, on the phone or on a computer. Phatic discourse is said to be used either for social reasons or for practical ones. If we treat verbal interaction as a special kind of goal-oriented social action, we shall see that phatic communication is aimed at the realization of situational goals (unlike other types of exchanges that are aimed at the realization of certain communicative goals). Thus, one of the aims of phatic discourse is to maintain and terminate verbal interaction. Let us consider the following adjacency pairs which contain almost automatic patterns of greetings, goodbyes: A: Good morning. B: Good morning. A: See ya! B: Bye. A: Hello. B: Hi. A: How are you? B: Fine. These habitual, spontaneous adjacency pairs present sequences in which the utterance of a first part immediately creates an expectation of the utterance of the second part of the same pair. This implies that the exchange of remarks is carried out unintentionally, mechanically, with no conscious effort. It should be strange to think that speakers doubt, hesitate or even think how to answer a greeting or parting. These phatic responses come out through spontaneous recognition of typical speech situations and automatic production of necessary phatic tokens and, moreover, no conscious outwork is required for the process of communication. Automatic verbal action, or, to be more exact, verbal action carried out on the subliminal level of consciousness, can also be carried out for practical reasons. For example, A: Thank you. B: Thank you. A: Thanks. B: You're welcome. A: Could you help me with this? B: Sure. A: Yeah. B: Okay.

Speaking about ease of processing, cognitive psychologists mention that the terms that are automatically retrieved from memory possess a high degree of salience. Hence, it would be reasonable for us to assume that the above mentioned samples of phatic discourse including automatic patterns of greetings, goodbyes can obtain a high degree of salience in the process of interaction.

Certain adjacency pairs allow for variations in the forms which are used to fill in the slots of the automatic communicative patterns. In this type of phatic discourse the retrieval of the ready-made formulae from memory depends on a certain amount of conscious outwork, taking into consideration certain linguistic and extralinguistic factors of communication (sex, age, familiarity, mood etc.). On account of this, as we see, the degree of salience is naturally reduced. For example, A: How are things? B: The usual. A: How are things going? B: So so. A: How are you doing? B: Not bad, thanks. Therefore, foreign language teaching necessarily includes not only practising these ready-made formulae but also indicating their appropriateness in different communicative situations. 
It has been stated that phatic discourse can also be aimed at the establishment of social relationships and agreement between the interlocutors (Паронян Ш., 2003). The latter do not pursue any communicative aims, they simply keep in contact in order to enhance tuneability, concord and to create an atmosphere of social harmony. This type of phatic discourse is usually carried on at the beginning of the conversation when the interlocutors need some "communicative" time to adjust to each other before entering into a more serious discussion. For example, in the following exchange the "phatic" discussion of the gift helps the interlocutors to establish agreement and enter into a conversation, having established certain positive interpersonal disposition.

Betty (opens the gift): Oh, it's beautiful. Max: It's a Benrus that's the top make. Betty: It's so stylish. Max: Look at that band that's fourteen- karat - not junk . Betty: It's expensive. (W.Hanly, The Light Bulb: 12).

There exists a set of topics for conducting this type of phatic discourse: weather, leisure, health. As we see, these topics are mainly associated with common knowledge - i.e. what everyone knows. They are culture-loaded, which means that they present specific national culture. They also vary from group to group, which means that they present the socio-psychological preferences of the speech community. Talk on weather, for example, in British community is used for conducting phatic communication. For example:

Sean: A fine night. The young man: It is. Sean: It must be up to at least fifty degrees on the damn thermometer. The young man: All of that. Sean: warm for this time of the year. The young man: I always said Dublin is the Riviera of Ireland. (S. Shepard, The First Night:43)

As we see, in this case the intentions of the interlocutors do not interact to create a meaningful unit. In fact, there is no cohesion of meaning. This is just a casual conversation which is carried on in order to maintain social cohesion. Conducting this kind of phatic communication requires a different degree of salience. The speaker's mind carries out conscious recall - recognition of certain formulae or constructions to realize the choice of verbal tokens in each case. The degree of salience in case of the above mentioned phatic discourse is reduced to a great extent, since the recognition of scripts of standard conversational settings as well as recall of stereotypical speech formulae concerning weather, leisure, health does not by all means require retrieval of ready-made and practiced conversational clichés. It includes a great deal of conscious outwork on the speaker's part.

Undoubtedly, the social factor becomes focal in this type of phatic discourse. Phatic communication becomes a strategic means for the successful realization of face-saving 
acts. Phatic discourse in which the social factor is predominant requires active conscious outwork on the speaker's part. Hence, it should be reasonable to suppose that it has a fairly low degree of salience - if any at all.

In summary, we can state that, the making of linguistic choices in the process of phatic communication comprises various degrees of salience - from repetition of readymade speech formulae through spontaneous recognition of the corresponding script to creation of new tokens through active recall.

As we see, the salience of linguistic choices is related to mental processes in memory - mind in society. Thus, socialization and enculturation of speech has established certain behavioral norms and expectations - linguistic as well as non-linguistic - prevalent in the community.

As a matter of fact, it should be mentioned that it is impossible to determine degrees of salience for all types of linguistic choice-making. Our research carried out on the example of standardized speech models was just an attempt of conscious insight into the infinite sphere of the subconscious, an attempt to see the unseen. As a final indication, I would like to express my agreement with the idea that much of what is involved in the process of actual linguistic choice-making takes place at a subliminal level and is beyond the sphere of conscious linguistic or psychological investigation.

\section{References:}

1. Brown G., Yule G. Discourse Analysis. Cambridge, 1983.

2. Capone A. Pragmatics for Exam Students, 2003. In: http.www.adobe.com.

3. Cook G. Discourse, Oxford, 2002.

4. Clark H., Van Der Wege M. Imagination in Discourse. In: The Handbook of Discourse Analysis ed. by Schiffrin D., Tannen D., Hamilton H., Cambridge, 2003.

5. Cutting J. Pragmatics and Discourse. London, 2002.

6. Halliday M.A.K. Explorations in the Functions of Language. London, 1975.

7. Jakobson R. Linguistics and Poetics. In: Style in Language ed. by Sebeok Th., Cambridge, 1975.

8. Malinovski B. The Problem of Meaning in Primitive Languages. In: The Meaning of Meaning ed. by Ogden C.K., Richards I.A., London, 1936.

9. Verschueren J. Understanding Pragmatics, New-York, 1999.

10.Паронян Ш. Единицы речевого общения в свете теории взаимодействия, Ереван, 2003.

11.Почепцов Г. Фатическая метакоммуникация В кн.: Семантика и прагматика синтаксических единств под ред. Сусова И., Калинин, 1981. 


\section{Sources of Data:}

12. Hanley W. The Light Bulb. In Mrs Dally has a Lover and Other Plays, New York, 1963.

13. Shepard S. The First Night. In Seven Plays, London, 1985.

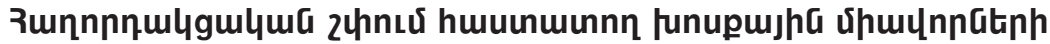

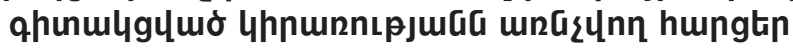

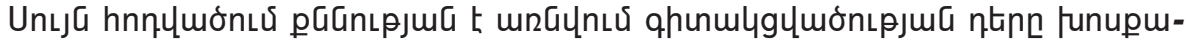

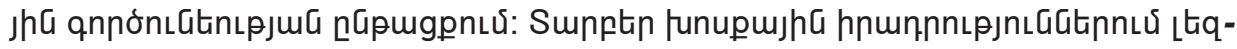

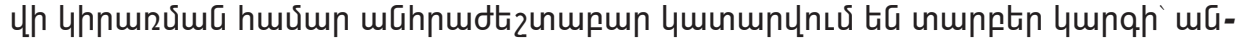

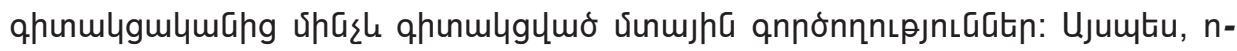

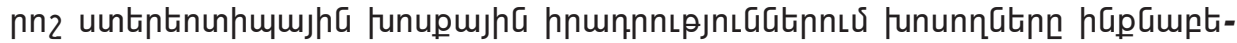

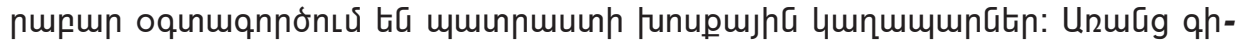

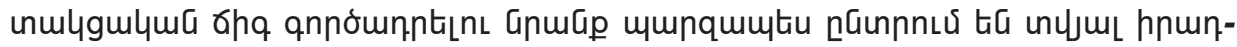

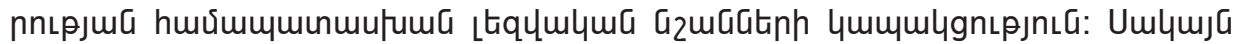

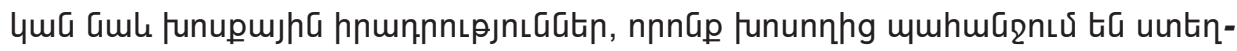

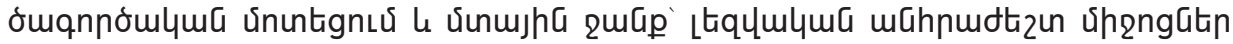
nGunptint:

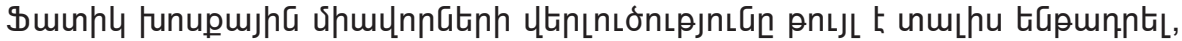

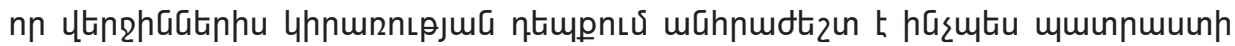

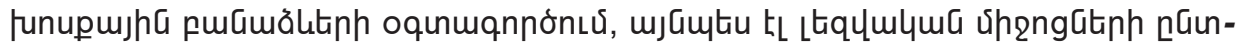

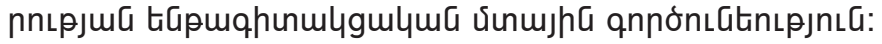

